\title{
Life in Hydrothermal Vents
}

\author{
Kamakhya Pada Biswas* \\ University of Animal and Fishery Sciences, India \\ *Corresponding author: Kamakhya Pada Biswas, India
}

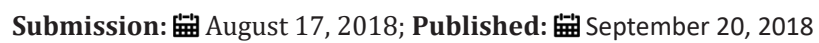

\section{Editorial}

Heat loving (thermophillic) animals love to live in places where temperature exceeds 80 degree Celsius, such as, hydrothermal vents. Hydrothermal vents arise where cold sea water interacts with freshly formed hot ocean crust along the chains of submarine volcanoes, called mid-ocean ridges. The basic requirements for hydrothermal circulation are a source of heat and a pathway for sea water to circulate within the rock. It represents significant cooling process for the planet. Hydrothermal activity is a part of the way in which the Earth works and is intimately linked to plate tectonics and occurs almost exclusively to ocean ridges. To Earth scientists, it represents a significant cooling process for the planet. For oceanographer's hydrothermal fluxes of chemicals, notably, iron, manganese, methane, hydrogen and hydrogen sulfide help to buffer the chemical balance of the ocean and atmosphere. The best estimates suggest that the entire volume of ocean is processed through high temperature vents every ten million years and through deep sea hydrothermal plumes every few thousand years. High temperature venting on the sea floor gives rise to flumes which ascend through the oceanic water column entraining sea water until they reach a level of neutral buoyancy some hundreds of meters above the sea bed. Subsequent lateral spreading of these plumes with their associated signatures in temperature, chemical tracers and suspended particulate material provides a means by which new hydrothermal vent sites can be located.

Submarine thermal springs, also called deep sea hydrothermal vents, have been discovered on the Galapagos Rift and on the East Pacific Rise. They are remarkable in two ways. Firstly, their physicochemical conditions are extreme, since the water emerging from the fissures is hot, anoxic, acidic and contains an enormous amount of hydrogen sulfide. This water mixes with normal surrounding oceanic water, which is cold ( 2 degree Celsius), contains oxygen at a pressure of more than 50 Torr, no hydrogen sulfide and a $\mathrm{pH}$ value around 7.5. Consequently, over a short distance, the physicochemical conditions change steeply. Secondly, in these special waters, a dense biomass is supported by the primary production of sulfide oxidizing bacteria. Large pogonophoran tube worms, clams, mussels and brachyuran crabs are found, some species of this group have never been observed elsewhere. Their physiology is beginning to be known. Hydrothermal activity gives rise to characteristic chemical signatures (sulfide and methane gradients), which vent

crustaceans may use to locate active hydrothermal fields, as well as thermal gradients ( 2 degree Celsius to greater than 360 degree Celsius). Light generated at the vents is enough to support vision in an otherwise aphotic world and could serve as a superfluous near field settlement hint if juveniles approaching the vents can detect it. Through hydrological cycle water is circulated through the depth of the Earth. It has long been suspected that surface material can be carried to the Earth's deep interior by subduction of ocean crust and sediment, as well as, the residue of ocean creation from depths back to the surface.

In the seismic area (85-degree N, 85-degree E), where volcanic activity was observed in 1999, extremely thick plumes were observed up to 1400 meter and were centred more than 1000 meters off the sea floor. Typical maximum rise height for hydrothermal plumes in the Pacific and Atlantic oceans are 200 to 400 meters. The plumes at 85-degree $\mathrm{E}$ in their thickness, height of rise and magnitude of signals indicate the most vigorous hydrothermal venting in the area. Sharp plume in both light scattering and temperature at 2009 meter between 8-degree $\mathrm{E}$ and 18-degree E, wide spread plume at 3100 to 3200 meters between 21-degree $\mathrm{E}$ and $3 \mathrm{e} 1$ degree $\mathrm{E}$ were identified along 1100 kilometres section of the Gakkel Ridge in the Arctic ocean. While investigating into the ecology of animals living deep water hydrothermal vents, the crab, Xenograpsus testudinatus have been found to live at enormously high densities around the sulfur rich hydrothermal vents in shallow water at depth less than 200 meters off Taiwan, even though this acidic environment $(\mathrm{pH}$ 1.75 to 4.60 ) is low in nutrients. Thousands of Xenograpsus crabs' swarms out of their crevices at slack water, when currents are weak or absent and feed frantically on the sea floor over an area of few square meters, on the vast quantity of zooplankton, that are killed by the vent's sulphurous plumes, and rain down like marine "snow". These opportunistic feeding behaviours explains how the crab are able to survive in the adverse toxic environment of these shallow hydrothermal vents.

When the water currents are weak or absent, the vent plumes are directed vertically, instantly killing any organism in their path and causing it to drop straight down the water column. This mass descending zooplankton has the appearance of falling snow. Dead fish and fine particulate matter also gradually precipitate around the vent. When the current increase and the deadly plumes alter the 
course, the dropping of the dead zooplankton ceases, and he crabs return to their crevices. As tides in Taiwan are semi-diurnal, crab feeding runs takes place twice daily. The crabs time their foraging to coincide with these marine snow falls to maximize their efficiency in harvesting the plankton kill. This opportunistic feeding behavior by Xenograpsus crabs has not been seen in any other hydrothermal organisms, represents a remarkable adaptation to their nutrient poor environment. The shallow water vents off Kneishan Island (121 degree 57 minute $\mathrm{E}$ and 24 degree 50 minute $\mathrm{N}$ ) in north eastern Taiwan erupt sulfurous plumes and bubbles of gas, mainly carbon dioxide, nitrogen, oxygen, sulfur dioxide and hydrogen sulfide through large smokers (2-6 meter in height) at 65 degree to 116 degree Celsius, where only two species of brachyuran crab, Xnovae insularis and Xnovae testudinatus have been found to live. More than four hundred new species have so far been found at vent sites, informing the discovery of one new species every two weeks on average throughout the past forty years. These organisms range from anaerobic microbes to the spectacular red-plumed tube worms, Riftia pachyptila which can reach several meters in length. In between Eyeless rift shrimp called Rimicaris exoculata residing at the vents of Atlantic, have been found to possess two reflective patches running down their backs. The patches which had never been noticed before, looked like sensor. It is thought that they might be highly modified eyes for sensing light.

Using a sensitive camera designed for astronomical imaging, for vent mapping expedition, to take picture of the seemingly pitchblack chimneys, the explorer found the vents to glow. Marshalling the evidence convinced the biologists that shrimp use their eyes (reflective patches) to keep them close enough to the vents to feed on bacteria, but far enough to prevent them being cooked by the ferocious heat. Scientists found photosynthetic bacteria living in the black depths. If further research shows that the creatures live by the vents all the time and do not visit from brighter areas, then these bacteria would be the first organisms ever found to photosynthesize without sun light. Adult species of vent dwelling crabs, Bathogrea thermydron also have naked retinal structures, like those of Rimicaris. Theearly "zoea" larvae of the crab, which live not in vents, but as deep-sea plankton, have normal apposition compound eyes. These eyes progressively lose their optics during development and turn into the naked, rather amorphous, retina of the adult. The pigments in the eye that respond to light also change. They are maximally sensitive to the blue light $(477 \mathrm{~nm})$ in the planktonic zoea larvae to blue green light $(479 \mathrm{~nm})$ in the later megalopa larvae, which already inhabit vents and finally to longer wave lengths blue green light $(489 \mathrm{~nm})$ on the adult eye.

Successive metamorphosis of eye anatomy and photo pigment content of the Pacific vent crab, Bathyograea thermydron have been observed in adaptation to the demands of transition from a larval habitat in the deep sea plankton to bathypelagic vent environment. Eyes of crab larvae (zoea) contain a short wavelength photopigment that is well matched to the dim blue light of mesopelagic waters. Descent towards the depth at which vent occurs and where crab settles (2500 meters) includes entry into the aphotic zone, where solar photon fluxes at visible wavelengths are insufficient to support vision. So, vision in the megalopa larvae, most sensitive in the blue-green wavelengths is an adaptation to detect bioluminescence in deeper bathypelagic waters. Near the bottom, hydrothermal vents generate light in the near infrared and visible portions of the spectrum. Sulfide oxidation at the vents generate chemiluminescence at visible wave lengths between $380 \mathrm{~nm}$ and $620 \mathrm{~nm}$. Crystalloluminescence, triboluminescence and sonoluminescence in the vent effluents contribuite to the visible light. The naked retina-eyes of the first juvenile crab are well suited to serve as photon gradient detectors, supplementing chemical and thermal senses for proper orientation towards the vent during settlement and assisting in the selection of an appropriate habitat for juvenile life. Eyes of third stage juvenile crabs are similarly adapted to detect dim light. Negative phototaxis to the vent light in settled crabs would prevent them from scalded, while foraging dangerously close to localized venting.
Creative Commons Attribution 4.0 International License

For possible submissions Click Here
Submit Article

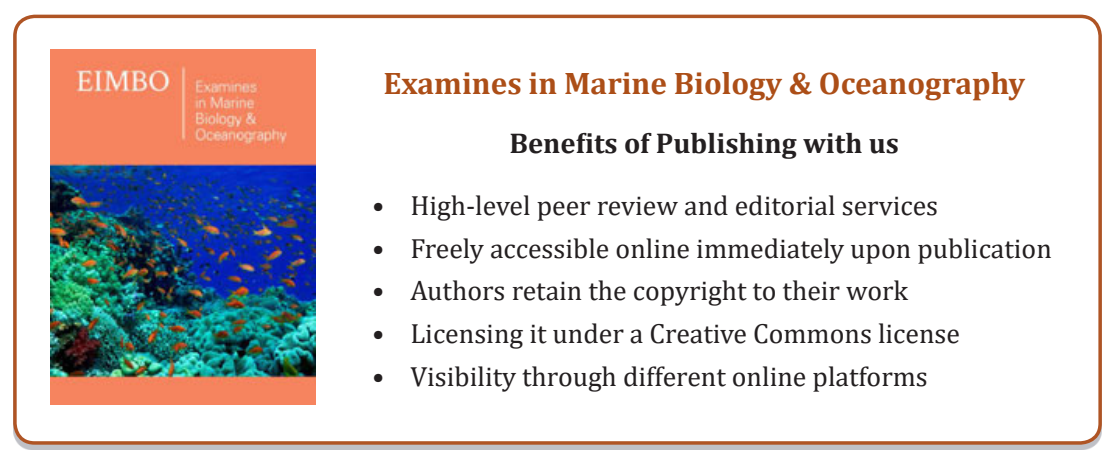

